\title{
Nationwide Assessment of Urban Surface Water Environment Status in China
}

\author{
Hongjie Gao, Peng Yuan, Ruixia Liu* , Lu Han, Yonghui Song \\ Chinese Research Academy of Environmental Sciences, Beijing 100012, China
}

\begin{abstract}
In this study, the assessment of nationwide urban water environment status was conducted based upon a method of integrating both $70 \%$ of objective water quality and $30 \%$ of standard compliance percent compared with national standard limit of GB3838-2002 for Class III. The impact factors on urban water environment status were discussed. The results showed that the status of urban water environment could be graded into 5 types in China. The population density, water resources, urbanized areas and so on were key impact factors on water environment. The study found that population density and urban built-up area had significantly negative effect on urban water environment status, and there was positive relationship between per capita water resources and urban water environment status. The results would provide the guidance for effective governance and management of urban water environment at national level.
\end{abstract}

\section{Introduction}

As we all know, urbanization has become a global prevailing trend all around world today. In particular, the urbanization rate in China dramatically increased from $17.9 \%$ in 1978 to $53.7 \%$ in 2013 [1]. In spite of unprecedented economic benefits brought about by urbanization, the rapid urbanization has also led to a series of social problems, such as environmental pollution, housing shortage, rising in unemployment, etc. Of these, water environmental pollution in urbanized area is one of key issues, which have led to a serious threat to people's health and faced great challenges, for instance, bad water quality, lack of water resources, highly frequent water pollution accidents and shortage of efficient water management system [2]. Therefore, improving urban water environment is one of the most important tasks that have been put forward in the "Water Pollution Control Action Plan" issued by the Chinese Government in 2015.

So far several approaches have been proposed for the assessment of water environmental quality, such as water quality index (WQI) [3,4], principal component analysis [5], analytic hierarchy process [6], grey relational analysis [7], etc. Among these methods, WQI evaluation has been widely used because of its simplity and high accuracy [8-10]. Especially the evaluation results by this method could truly reflect the degree of surface water pollution.

\footnotetext{
* Corresponding author: liurx@creas.org.cn
} 
Nevertheless, there are still many needs for the development of practical assessment method and nationwide statistical outline of urban surface water environment status based on the developed method, further for future establishment of effective and standardized management system. In this study, taking both objective water quality assessment and subjective effort of local government for pollution control in consideration, a modified WQI method was applied for the comprehensive assessment of urban water environment status.

\section{Materials and Methods}

\subsection{Study area and data collection}

Twenty one water quality indicators at 1940 national sections monitored in 2014 were collected and used for the calculation of water quality index of indicator I $(C W Q I(i))$, as expressed as the ratio of concentration of indicator $I(C(i))$ and standard value of indicator $I$ in GB3838-2002 for Class III $\left(\mathrm{C}(i)_{s}\right)$ :

$$
C W Q I(i)=C_{(i)} / C(i)_{S}
$$

Those elements included $\mathrm{pH}$, dissolved oxygen, permanganate index, biochemical oxygen demand, ammonia, petroleum, volatile phenol, mercury, lead, total phosphorus, chemical oxygen demand, copper, zinc, fluoride, selenium, arsenic, cadmium, chromium (VI), cyanide, anionic surfactants and sulfides. The 334 cities in China were selected for the statistical analysis and water environment assessment.

\subsection{Assessment method}

Status assessment of urbanized surface water environment was based on the both objective water quality and standard compliance percent compared with national standard limit of GB3838-2002 for Class III, as shown in equation (2):

$$
F=F_{q} \times 70 \%+F_{c} \times 30 \%
$$

where $F$ is score of urban surface water environment, $F_{q}$ is score of urban surface water quality and $F_{c}$ is score of standard compliance percent. The $F_{c}$ and $\mathrm{F}_{q}$ values can be calculated according to equations (3) and (4):

$$
\begin{gathered}
F_{c}=(1-k / m) \times 100 \\
F_{q}=C W Q I_{\text {city }} / C W Q I_{\max } \times 100
\end{gathered}
$$

where $k$ is numbers of monitoring sites meeting target and $m$ is total numbers of monitoring sites. $C W Q I_{\max }$ is the largest value among 338 cities and $C W Q I_{\text {city }}$ can be expressed as following equation (5):

$$
C W Q I_{\text {city }}=\left(\sum C W Q I_{(i) r i v e r} \times M+\sum C W Q I_{(i) l a k e} \times N\right) /(M+N)
$$

where $M$ is the section numbers of the river in the city and $N$ is the site numbers of lake in the city.

\subsection{Classification of urban water environment}

According to the score of urban surface water environment $(F)$, the status of urban surface water environment could be graded as "excellent" $(F \geq 85)$, "good" $(85>F \geq 75)$, "fair" (75>F $\geq 60)$, "pollution" $(60>F \geq 40)$ and "heavy pollution" $(F<40)$, as presented in Table 1. 
Table 1. Classification of urban water environment.

\begin{tabular}{|c|c|}
\hline Score $(F)$ & Types \\
\hline $\mathrm{F} \geq 85$ & Excellent \\
$85>\mathrm{F} \geq 75$ & Good \\
$75>\mathrm{F} \geq 60$ & Fair \\
$60>\mathrm{F} \geq 40$ & Pollution \\
$\mathrm{F}<40$ & Heavy pollution \\
\hline
\end{tabular}

\section{Results and Discussion}

\subsection{Distribution map of urban water environment status}

Based on the statistical data and calculation of 21 water quality indicators and standard compliance percent in 1940 national sections of 334 cities, the nationwide distribution of surface water environment status was shown in Figure 1. The results revealed that overall status corresponded to "normal distribution", e.g. the cities with "good" and "fair" water environment status accounted for $34 \%$ and $37 \%$ among 334 cities, respectively. Only 10 and $5 \%$ of cities were in water environment status with "excellent" and "heavy pollution" levels. This reflected the regional differences in water environment, implicating great significance for the differentiated management.

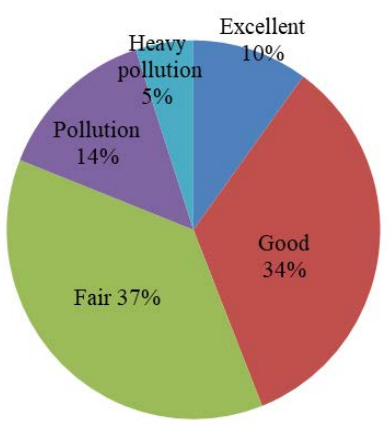

Figure 1. Distribution map of urban water environment status

\subsection{Impact of population density on urban water environment status}

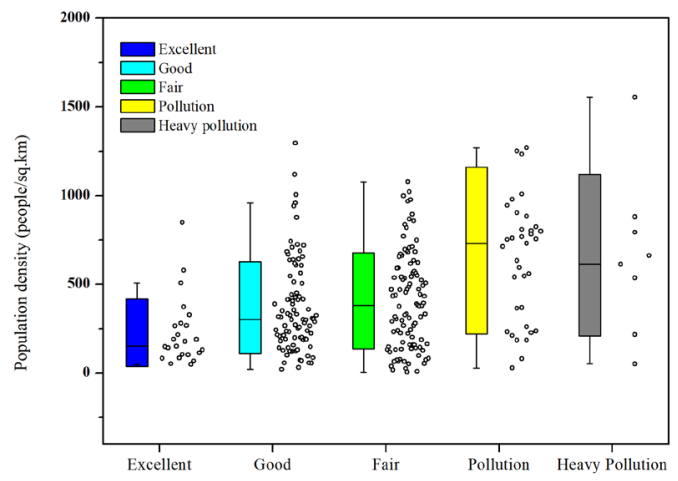

Figure 2. Effect of population density on water environment status 
Figure 2. It was observed that there was negative impact on water environment status with increased population density. When the population density was over 500 people $/ \mathrm{km}^{2}$, the water environment condition of city was getting worse with most of them in "pollution" or "heavy pollution" levels. Of the cities with"excellent", "good" and "fair" water environment condition, more than $70 \%$ of those were in the population density less 500 people $/ \mathrm{km}^{2}$. These results implicated that rapid urbanization would lead to the water environment deterioration, which had to take effective management and controlling measure to improve water quality.

\subsection{Relationship between water resources and water environment status}

The dependence of water environment status on water resources was presented in Figure 3. The results indicated that the 13 cities with "heavy pollution" were all in severe water shortages and extreme water resource shortages with per capita water resources below 1000 cubic meters. Most of cities with per capita water resources higher than 1500 cubic meters were in "excellent" and "good" water environment conditions.

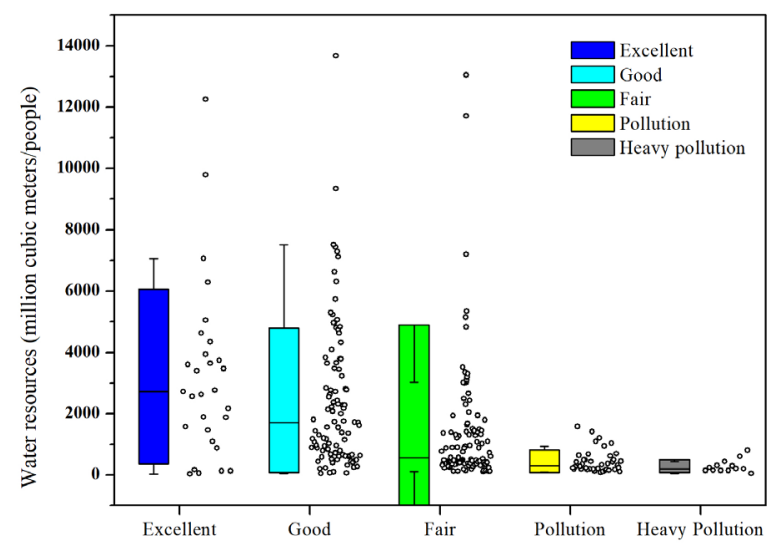

Figure 3. Dependence of water environment status on water resources

\subsection{Impact of built-up area on urban water environment status}

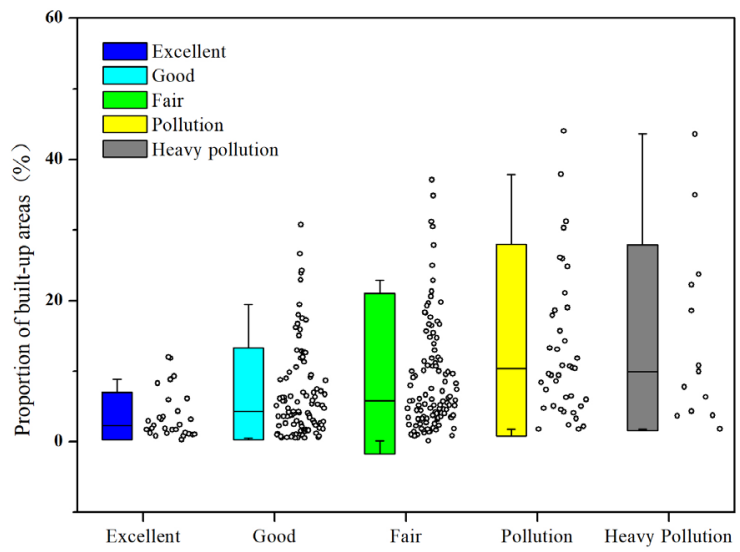

Figure 4. Effect of urbanized areas on water environment status 
Similarly, there was a corresponding relationship between proportion of built-up areas and urban water environment status, e.g. the higher the proportion of built-up areas, reflecting higher level of urbanization, the worse the water environment was, as shown in Figure 4. Among statistical cities with "pollution" or "heavy pollution" water environment conditions, more than $50 \%$ of those were in proportion of built-up areas higher than $10 \%$.

\section{Conclusions}

An assessment method of urban water environment status was established by integrating $70 \%$ objective water quality score and $30 \%$ compliance score. The nationwide status of urban water environment could be classified into 5 types in China. The statistical results showed that there were close relationships between urban water environment status and population density, per capita water resources and proportion of urbanized area. This information would offer comprehensive understanding of urban water environment status at national level and further for effective governance of urban water environment.

The acknowledgements: This work was supported by the Ministry of Ecology and Environment of the People's Republic of China.

\section{References}

1 OECD Urban Policy Reviews: China 2015. OECD. 18 Apr 2015. p. 37. doi:10.1787/9789264230040-en. ISBN9789264230033.

2 C.C. He, X.Q. Su, X.Q. Bu, Z. Xie, Urbanization and Environmental Sustainable Development, Adv. Mater. Res., 1092-1093, 1629-1633 (2015).

3. L. Z. Hu, H. Hu, Fuzzy complex index in water quality assessment of municipalities, J. Wat. Resour. Prot., 2(9), 809-813 (2010).

4. S.Y. Li, Q.F. Zhang, Assessing the water quality in the water source area of the middle route of the South to North Water Transfer Project (Danjiangkou Reservoir) using a water quality index method, Res. Environ. Sci., 21(3), 61-68 (2008) (in Chinese).

5. L. Sun, Comparison between performance of principal component analysis and fuzzy analysis in water quality evaluation, Environ. Sci. Manag., 36(8), 178-181(2011) (in Chinese).

6. Z.L. Pang, H.J. Chang, Y. Y. Li, et al, Analytical hierarchy process ( AHP ) evaluation of water quality in Danjiangkou reservoirsource of the middle line project to transfer water from south to north China, Acta Ecologica Sinica, 28 (4), 1810-1819 (2008) (in Chinese).

7. X.C. Zhao, Applicaton of gray relational analysis method in evaluation of water quality in Qingdao part of Dagu River, J. Hydroecol., 2(5), 115-118 (2009) (in Chinese).

8. T. Hurley, R. Sadiq, A.Mazumder, Adaptation and evaluation of the Canadian Council of Ministers of the Environment Water Quality Index(CCME WQI) for use as an effective tool to characterize drinking source water quality, Wat. Res., 46 (11), 3544-3552 (2012).

9. P. Debels, R.Figueroa, R. Urrutia, et al., Evaluation of water quality in the Chilla'n River (Central Chile) using physicochemical parameters and a modified water quality index, Environ. Monit. Assess., 110(1), 301-322 (2005).

10. A. Lumb, T.C. Sharma, J.F. Bibeault, et al., A comparative study of USA and Canadian water quality index models, Water Qual Expos Hea. 3(3), 203-216 (2011). 